\title{
EDUCAÇÃO POPULAR E EDUCADORES SOCIAIS NAS UNIVERSIDADES: A Luta dos Movimentos Sociais
}

\author{
Fernanda dos Santos Paulo ${ }^{1}$ \\ Elenita Lopes da Silva²
}

\section{RESUMO}

O artigo discute a relação trabalho-formação de educadores sociais que atuam nas periferias urbanas de Porto Alegre - RS. Apresentamos as categorias educador popular e educador social, e ponderamos acerca dos espaços educativos de Educação Não Escolar. As categorias são contextualizadas, histórico-politicamente, com o uso da pesquisa participante. Além disso, resgatamos a importância dos movimentos sociais na perspectiva da Educação Popular, articulando às áreas Educação e Serviço Social.

Palavras-chave: educação popular e universidade; educação não escolar; educadores sociais.

\section{POPULAR EDUCATION AND SOCIAL EDUCATORS IN UNIVERSITIES: FIGHTING SOCIAL MOVEMENTS}

\section{ABSTRACT}

This article discusses the work-training relationship of social educators who work in the urban peripheries of Porto Alegre - RS. We present the categories popular educator and social educator, and we ponder about the educational spaces of Non-School Education. The categories are contextualized, historically-politically, with the use of participant research. In addition, we rescued the importance of social movements in the perspective of Popular Education, articulating to the areas of Education and Social Work.

Keywords: popular education and university; non-school education; social educators.

Recebido em: 22/5/2019

Aceito em: 9/7/2019

\footnotetext{
1 Autora correspondente. Universidade do Oeste de Santa Catarina - Programa de Pós-Graduação em Educação. Getúlio Vargas, Flor da Serra. Joaçaba/SC, Brasil. CEP 89600-000. http://lattes.cnpq.br/3839347399904355. https://orcid.org/0000-0002-8022-9379. fernandaeja@ yahoo.com.br

2 Associação de Educadores Populares de Porto Alegre - Aeppa. https://orcid.org/0000-0002-9331-8207
} 


\section{INTRODUÇÃO}

O artigo origina-se da nossa participação no movimento de Educação Popular via Associação de Educadores Populares de Porto Alegre (Aeppa). Nesse espaço participam educadores de contextos escolares e não escolares, autodenominando-se educadores populares (PAULO, 2013). Esses educadores mobilizam-se para lutar pela formação universitária e política com base em Paulo Freire.

Neste artigo o foco é a Educação Não Escolar, em especial a executada por educadores sociais, trabalhadores do Serviço de Convivência e Fortalecimento de Vínculos (SCFV). Há, na Aeppa, todavia, outros núcleos: da Educação Infantil, da Educação de Jovens e Adultos, dos Oficineiros, e um, mais geral, chamado Formação Política.

No núcleo da Educação Não Escolar há subnúcleos: do Ação Rua, do Serviço de Convivência e Fortalecimento de Vínculos e outros contextos educativos fora da escola (pedagogo não escolar, pedagogia hospitalar, etc.).

A pesquisa trata da seguinte questão: Cabe à universidade formar o educador social trazendo a educação popular como concepção teórico-prática brasileira para o currículo? Uma segunda questão, entrementes, levou-nos à pergunta central: Quais dificuldades as educadoras sociais encontram para ingressar e/ou permanecer nas universidades?

Para responder essas questões os nossos objetivos são: analisar, a partir das entrevistas, as demandas formativas universitárias do educador social, trabalhador do Serviço de Convivência e Fortalecimento de Vínculos. Quanto aos objetivos específicos, são estes: a) identificar os limites e possibilidades de as demandas formativas do educador social adentrarem na universidade a partir das entrevistas; b) fomentar a discussão sobre a formação universitária do educador social no Brasil; c) apresentar os avanços formativos a partir das lutas do movimento social que vem representando os educadores sociais de Porto Alegre.

Esta pesquisa caracteriza-se como empírica, com coleta de dados realizada na Aeppa. Foram feitas observações em um curso para educadores sociais na perspectiva da Educação Popular, realizado pela Faculdade de Educação da Universidade Federal do Rio Grande do Sul (UFRGS), juntamente com a Aeppa, o Centro de Assessoria Multiprofissional (Camp), o Consejo Educación Popular de América Latina y Caribe (Ceaal), o Instituto Social Brava Gente e o Movimento de Educação Popular, com apoio do Fórum de Educadores Sociais de Porto Alegre-RS. O curso foi demandado pela Aeppa e acolhido pelo professor Paulo Peixoto de Albuquerque, vinculado ao Departamento de Estudos Básicos da Faculdade de Educação da UFRGS.

O curso tem a seguinte denominação: Educadores Sociais e compromisso cidadão, com início em 5 de abril de 2019, sendo executado interinstitucionalmente no espaço cedido pelo Camp. Os encontros são realizados nas sextas-feiras (noite) e sábados (manhã e tarde). Quanto às observações realizadas para este artigo, tivemos como centralidade o acompanhamento de educadoras, militantes da Aeppa e MEP, igualmente trabalhadoras do SCFV. 
Realizamos um levantamento bibliográfico sobre o tema e os trabalhos localizados inserem-se como referencial teórico. A nossa abordagem teórico-metodológica é qualitativa, com uso de entrevistas semiestruturadas. Para essas entrevistas foram convidados educadores da Associação de Educadores Populares de Porto Alegre, vinculada ao Movimento de Educação Popular; entre esses educadores estão trabalhadores do Serviço de Convivência e Fortalecimento de Vínculos (quatro educadores sociais, dois coordenadores pedagógicos e dois dirigentes de instituições) e um representante da comissão coordenadora da Aeppa.

\section{INSTRUMENTOS DE PESQUISA E A RELAÇÃO DO MOVIMENTO SOCIAL POPULAR COM A UNIVERSIDADE}

Paulo Freire é o autor referência da Educação Popular e da metodologia embasada nessa concepção de educação e de pesquisa. Da mesma forma, Brandão (1980) é um dos teóricos que mais tem produções acerca da Educação Popular, fazendo referência aos movimentos sociais. Utilizando-nos de Freire (1983), nos colocamos como participantes da pesquisa e como pesquisadoras engajadas, pois "deste modo, fazendo pesquisa, educo e estou me educando com os grupos populares" (p. 36).

Os participantes do nosso estudo, vinculados ao Grupo de Estudos e Pesquisa Paulo Freire e Educação Popular da Aeppa, foram entrevistados nos locais previamente agendados. As atividades de que os educadores sociais participam e que foram acompanhadas ocorreram na Aeppa e no curso de educadores sociais. Todos os participantes estão vinculados ao Serviço de Convivência e Fortalecimento de Vínculos, e as questões elaboradas para a entrevista semiestruturada contemplaram temas sobre formação e demandas formativas a partir do trabalho, relacionando a luta dos movimentos sociais filiados à temática da educação.

Algumas questões referiam-se diretamente às atividades específicas dos participantes da nossa pesquisa. No caso da entrevista com dirigente da Aeppa, tratamos das lutas por formação universitária na perspectiva da Educação Popular para educadores sem formação. Já a entrevista com dirigente do espaço que executa o SCFV, abordamos o tema da formação do educador do SCFV e o trabalho que é realizado na instituição. Em geral, objetivou-se identificar o entendimento dos educadores sociais do Serviço de Convivência e Fortalecimento de Vínculos sobre os saberes necessários ao seu fazer pedagógico, e se esses saberes devem ou não serem trabalhados pela universidade. No tocante às coordenadoras, o intuito foi investigar quais saberes teórico-práticos da universidade Ihes fizeram falta no seu contexto de trabalho.

Os educadores sociais entrevistados possuem mais de quatro anos de atuação no SCFV, trabalhando em Organizações Sociais conveniadas com a Fundação de Assistência Social e Cidadania de Porto Alegre no Rio Grande do Sul. As coordenadoras possuem curso de Pedagogia ou estão em curso. $O$ critério de escolha foi estar nessa função e no SCFV por mais de quatro anos. Os dirigentes foram eleitos na sua comunidade, e o espaço de execução do trabalho é em associação de moradores.

Foram feitas dez questões que se desdobraram em outras, conforme necessidade dos participantes da pesquisa. A "entrevista semiestruturada [...] Ihe permitirá esboçar novas linhas de inquisição, vislumbrar outras perspectivas de análise e de interpretação 
no aprofundamento do conhecimento do problema" (TRIVIÑOS, 1987, p. 132). Essa técnica de coleta de dados contribui para que possamos nos utilizar da Educação Popular e de Paulo Freire como fundamento teórico-metodológico, pois exige diretividade, diálogo, criticidade, escuta e problematizações (FREIRE, 1987).

As análises das entrevistas não são apenas descritivas, pois partimos da compreensão de que

Sistematizar permite, assim, diferenciar os elementos constantes dos ocasionais; os que ficaram sem continuidade no trajeto, os que incidiram em novas pistas e linhas de trabalho, os que expressam vazios que apareceram muitas vezes. Assim, permite determinar os momentos de aparecimento, de consolidação, de desenvolvimento, de ruptura, etc., dentro do processo e como os diferentes fatores comportaram-se em cada um deles. Nesse sentido, a sistematização possibilita entender a lógica das relações e contradições entre os diferentes elementos, localizando coerências e incoerências: por exemplo, entre a dinâmica do processo particular que realizamos e os desafios que a dinâmica social geral havia colocado para nossas práticas (JARA, 2006, p. 30).

Nesse sentido, as experiências da Aeppa e as entrevistas com educadoras do SCFV nos servem para buscar responder à questão que nos indaga: Quais dificuldades as educadoras sociais encontram para ingressar e/ou permanecer nas universidades? As entrevistas, no entanto, serão utilizadas ao longo do texto, cujo conjunto de reflexões servirá para problematizarmos o lugar da universidade no processo de formação dos educadores sociais.

Os instrumentos de pesquisa são fundamentados pelos saberes construídos academicamente e ressignificados na relação entre o Movimento Social Popular e a Educação Popular. Paulo (2013) apresenta uma reflexão associando a temática de estudo, na concepção dialética, na perspectiva da Educação Popular, à tensão permanente entre o militante de base e o cientista social, bem como o observador e o participante (BRANDÃO, 2006). Em outras palavras, a pesquisa de cunho participante é um convite à aproximação entre os Movimentos Sociais e a universidade.

A partir da introdução, o texto está dividido em cinco partes: a) Contexto da Aeppa; b) Espaço de trabalho e concepções de educação bem como de educadores/as sociais e educadoras/es populares; c) Os Educadores Sociais e Educadores Populares do SCFV; d ) Universidade e Educação Popular: Reflexões a Partir das Entrevistas; e, f) Considerações finais.

\section{A ASSOCIAÇÃO DE EDUCADORES POPULARES DE PORTO ALEGRE (AEPPA) E O SERVIÇO DE CONVIVÊNCIA E FORTALECIMENTO DE VÍNCULOS (SCFV)}

A Aeppa é um movimento popular que surge em 1990, sendo formalizada no ano 2000. A luta maior desse movimento é por formação inicial e continuada de educadoras/es populares. Por educador/a popular a Aeppa entende que é toda pessoa que se reconhece como tal, independentemente de sua formação e ocupação profissional (PAULO, 2010, 2013). O Estatuto da Criança e do Adolescente (Lei Federal 8069/1990 ECA) foi o que inspirou o surgimento da Aeppa.

Algumas educadoras populares são trabalhadoras do contexto não escolar - foco deste trabalho. Outras atuam na educação escolar, sobretudo na Educação Infantil e na Educação de Jovens e Adultos. 
Sobre a luta por formação, segundo documentos da Aeppa, as conquistas foram: educação em nível médio, superior (graduação e especialização), cursos de extensão e formação continuada livre (PAULO, 2018).

A Aeppa, como pode ser observado, tem como foco a luta por formação na perspectiva da Educação Popular. Nós participamos da Aeppa como militantes e fomos bolsistas de Pedagogia no Centro Universitário Metodista IPA. Desde as nossas experiências no SCFV nos perguntávamos sobre questões relacionadas ao trabalho dos educadores sociais e ao tipo de formação.

Observamos que esses educadores, assim como nós, trabalham nos espaços de acolhimento de crianças, adolescentes e suas famílias. A comunidade representa o seu espaço de atuação, pois, normalmente, é uma associação de moradores.

A Fundação de Assistência Social e Cidadania (Fasc) não tem se preocupado em discutir a formação superior para educadores sociais, tampouco em trabalhar a concepção de Educação Popular. A Fasc é um órgão do governo municipal, cuja parceria com as Organizações Sociais visa a atender crianças e adolescentes, principalmente dentro das comunidades, a partir da política da Assistência Social, especialmente do Sistema Único da Assistência Social (Suas). O SCFV compõe a Proteção Social Básica, que objetiva complementar o trabalho social com famílias, prevenindo a ocorrência de situações de vulnerabilidade e risco social.

Conforme a Secretaria Especial de Desenvolvimento Social, o SCFV é um Serviço da Proteção Social Básica do Sistema Único da Assistência Social, cujo objetivo é prevenir situações de vulnerabilidades sociais em todas as dimensões: culturais, educativas, familiares, comunitárias, etc. $O$ foco desse serviço é o sujeito que está em situação de vulnerabilidade social decorrente, sobretudo, da pobreza ou fragilização de vínculos sociais e afetivos.

No caso particular do SCFV, ele realiza atendimentos em grupo, com atividades culturais, artísticas, esportivas, dentre outras, com a dimensão educativa, de acordo com a idade de cada sujeito, denominado pela política de assistência social como usuário do serviço público. Esse serviço pode ser ofertado no Centro de Referência da Assistência Social (Cras) ou nos Centros de Convivência Comunitários. Em Porto Alegre o SCFV é complementar ao Serviço de Proteção e Atendimento Integral à Família; isto é, os dois serviços caminham juntos, com o objetivo de fortalecer as relações familiares e comunitárias dos usuários, bem como contribuir para o aumento da qualidade de vida destes. Em Porto Alegre a maior parte dos atendimentos das políticas de assistência social acontece por meio das Organizações Sociais Não Governamentais, mediante Regime de Colaboração com o munícipio; nesse caso, com a Fundação de Assistência Social e Cidadania (Fasc). Esse Órgão, até março de 2019, tinha 133 instituições parceiras (terceiro setor) executando alguma política municipal. É nesse espaço que as educadoras e educadores sociais trabalham. Os usuários do SCFV são organizados em grupos a partir de faixas etárias ou intergeracionais:

1. Crianças até 6 anos;

2. Crianças e adolescentes de 6 a 15 anos;

3. Adolescentes de 15 a 17 anos; 
4. Jovens de 18 a 29 anos;

5. Adultos de 30 a 59 anos;

6. Pessoas idosas.

A forma de acessar a política (SCFV) é via Centro de Referência da Assistência Social (Cras) do seu município; no caso do nosso lugar de estudo, é Porto Alegre. A Resolução CNAS no 9, de 15 de abril de 2014, ratifica e reconhece as Ocupações e as áreas de ocupações profissionais de nível Médio e Fundamental de escolaridade do Sistema Único de Assistência Social - Suas -, em consonância com a Norma Operacional Básica de Recursos Humanos do Suas. Nesse último documento, de 2006, não há menção ao educador social. Já na Resolução CNAS no 9, de 15 de abril de 2014, menciona-se o educador social como um trabalhador que compõe a equipe de referência do SCFV.

O trabalho dos educadores sociais/orientadores sociais, segundo a Resolução CNAS no 9, de 15 de abril de 2014, é uma função exercida por profissional com, no mínimo, nível Médio de escolaridade, cuja atuação junto ao(s) grupo(s) do SCFV é a de criação de um ambiente de convivência participativo e democrático. As atribuições desse profissional são, sem dúvida, educativas, destinando-se a desenvolver atividades socioeducativas, de convivência e de socialização, visando à defesa e garantia de direitos; além disso, o profissional é responsável por acompanhar e registrar a assiduidade dos usuários por meio de instrumentais específicos, como listas de frequência, atas, sistemas eletrônicos próprios, etc.

Na Aeppa busca-se, a partir de reuniões e formações junto aos educadores sociais, trabalhar esses fazeres e saberes, buscando pautar a importância da formação para além do nível Médio. De um modo mais amplo, nas universidades não contamos com a discussão sobre a necessidade de formação em nível superior para os educadores sociais, e pouco se trabalha a educação não escolar, sobretudo na área da educação. Na área do Serviço Social são incipientes os trabalhos sobre educadores sociais, com mais prevalência no tema do SCFV. Essa discussão tem se dado mesmo é nos Movimentos Sociais, como na Aeppa e em outras instituições, que vêm promovendo debates em defesa da Educação Superior como exigência para atuação como educador social. Algumas das instituições que, assim como a Aeppa, defendem a formação universitária são:

1. Eduso Brasil - Regional Sul

2. Coletivo de Pedagogia Social e Educação Popular - UFRGS

3. Fórum de Educadores Sociais de Porto Alegre - RS

4. Fórum de Educadores Sociais de São Leopoldo - RS

\section{ESPAÇO DE TRABALHO E CONCEPÇÕES DE EDUCAÇÃO BEM COMO DE EDUCADORES/AS SOCIAIS E EDUCADORAS/ES POPULARES}

Os movimentos sociais foram os principais espaços da educação não escolar, como podemos observar a seguir:

Os movimentos foram pioneiros na utilização dos processos de educação não formal, anteriores aos programas e projetos sociais das ONGs, que são dos anos de 1980 para cá. Já nos anos de 1970, quando tínhamos movimentos ligados às pasto- 
rais religiosas, ou às comunidades eclesiais de base, a educação não formal esteve presente, por exemplo, na aprendizagem para se fazer leituras do mundo (GOHN, 2013, p. 15).

As práticas de Educação Não Escolar, até pouco tempo, eram reconhecidas como Educação Não Formal. Podemos afirmar que, até 1990, as atividades, de fato, não eram institucionalizadas, tendo, portanto, características da Educação Não Formal, como define Gohn (1999, p. 15, p. 17):

Consideramos que o não formal é profundamente diferente do informal, tem campo próprio, e é a novidade a ser tratada, na pesquisa empírica e no trabalho teórico-acadêmico voltado para a produção de conhecimento. [...]. Na educação não formal, os espaços educativos localizam-se em territórios que acompanham as trajetórias de vida dos grupos e indivíduos, fora das escolas, em locais informais, locais onde há processos interativos intencionais (a questão da intencionalidade é um elemento importante de diferenciação).

Ainda conforme a autora, por muitos anos o não formal foi tratado como a não educação ou a educação de valor menor, pois "o senso comum e a mídia usualmente não vêem e não tratam como educação porque não são processos escolarizáveis" (2010, p. 34). A Educação Não Escolar, termo utilizado por nós, contudo, não significa negar os processos escolarizados. Trata-se de uma categoria conceitual que dá um novo e diferente significado à educação fora da escola. No lugar de não formal, o não escolar significa que existe educação fora da escola que pode ser formalizada ou informalizada. Cabe conhecer o lugar e a serviço de que aquele projeto de educação se dirige. A Educação Formal pode dar-se na escola (como já sabemos) ou em outros espaços não escolares (aqui reside a novidade). O SCFV não é uma Educação Informal, tampouco uma educação não formal ou formal no significado de escola (PAULO, 2010, 2013).

Ainda conforme Paulo (2013), na sociedade brasileira, após a Constituição Federal de 1988, projetos e programas oriundos das políticas sociais assumem um caráter institucionalizado. Nasce, então, a política da assistência social, e, com ela, vimos a expansão do associativismo e a criação de Organizações Não Governamentais (ONGs) como espaço de execução das políticas sociais. Os anos de 1990 são tempos dourados para o terceiro setor, quando as ONGs assumem a chamada Educação Não Formal como atividade de inclusão social via caridade e benevolência. Elas, aos poucos, vão compreendendo que a assistência social não visa a políticas assistencialistas, mas de minimização das desigualdades sociais.

No Brasil podemos afirmar que o Terceiro Setor, como o conhecemos, data às ações da Igreja Católica como principal instituição que desenvolvia ações de assistência social até o século 19 e metade do século 20. As suas atividades concentravam-se na promoção da saúde e da educação. Desse período surgem asilos, orfanatos, Santas Casas de Misericórdia e colégios católicos, reconhecidos como instituições voluntárias de cunho religioso cristão. Depois, o Terceiro Setor passou a compor interesse do Estado no período do governo de Getúlio Vargas. Nesse governo há uma preocupação com as políticas públicas, as quais foram executadas nas organizações sem fins lucrativos. A Igreja continuava tendo papel importante na prestação de serviços sociais, com repasse financeiro do Estado. 
No governo militar o Terceiro Setor compreende o período de resistência, em que a sociedade se mobilizou em defesa da questão social, surgindo o debate político em prol dos pobres e das políticas sociais. Nos anos de 1980 o Terceiro Setor emerge como parceiro do Estado; porém, é com essa parceria que se inicia um movimento de diminuição da execução direta das políticas sociais via Estado. As questões sociais são, nesse período de redemocratização do país, um assunto importante, emergindo o tema da cidadania e dos direitos como pauta prioritária dos movimentos sociais.

Nos movimentos sociais havia os educadores populares, os quais eram militantes de uma causa. Observamos que, no caso das ONGs, os educadores desses tempos eram, na maioria, voluntários. Alguns recebiam ajuda de custo e salário como recreacionista ou instrutor. O campo da educação não formal era concebido como um "cuida-se" ou como atividades para crianças pobres necessitadas. Pouco se discutia ou se refletia o espaço (campo de atuação) como um lugar educativo e consubstanciado por concepções político-pedagógicas (PAULO, 2013).

Nos anos de 1990 o Terceiro Setor adentra-se, especialmente na área social, com o objetivo de trabalhar a questão social em vários bairros, cidades e vilas. Viu-se expandir os objetivos das ONGs, cuja intenção foi a de ampliar o lugar e área de atuação. Entraram na área da educação, saúde e assistência social, utilizando o financiamento público.

Ao longo da década de 1990 e anos 2000 a expansão do Terceiro Setor, no Brasil, fez com que a profissão do educador social surgisse. O aparecimento de diversas ONGs, com a finalidade de executar projetos governamentais com interesses sociais, é um fator marcante.

Muitos movimentos comunitários institucionalizaram-se com o argumento de contribuir para o desenvolvimento social, econômico e cultural da sua comunidade, e contaram e contam com o financiamento do Estado; outros com empresas, órgãos transnacionais e bancos internacionais, mantendo a ênfase em ações públicas.

Neste texto trataremos de instituições de pequeno porte, a maioria associações que executam políticas sociais via regime de colaboração com o Estado. Essas possuem uma história vinculada aos movimentos populares de Porto Alegre, e, comprovadamente, provocam impactos locais na execução da educação infantil e do contraturno (SCFV) para crianças e adolescentes das periferias, aglutinando serviços sociais e educativos por meio de uma rede de instituições públicas não estatais.

\section{Os Educadores Sociais e Educadores Populares do SCFV}

Ser educador/a popular, conforme Paulo $(2013,2018)$, não é profissão, não está relacionado ao tipo de tarefa desenvolvida (escolar ou não escolar, ser médico/a ou educador/a social, etc.), mas a uma opção, fundamentada pela Educação Popular. No texto de Paulo e Santos (2017) as autoras definem o que é ser educador/a social e ser educador/a popular, apresentando aproximações e distanciamentos. Conforme o livro organizado por Paulo, Seabra e Pavani (2018), ser educador popular e educador social pode ser conferido no quadro a seguir: 
Quadro 1 - Registros de Educadores

\begin{tabular}{|l|c|}
\hline & Página \\
\hline $\begin{array}{l}\text { O educador da escola pública que luta pelo direito do educando a ter acesso aos } \\
\text { bens culturais produzidos pela humanidade é um fazedor da Educação Popular. }\end{array}$ & 69 \\
\hline $\begin{array}{l}\text { O educador social pode, com a arteterapia, resgatar o potencial humano do } \\
\text { sujeito aprendente, potencializá-lo e empoderá-lo para superar suas dificuldades, } \\
\text { que podem, inclusive, ser de ordem emocional. }\end{array}$ & 72 \\
\hline O educador social é um facilitador desse processo [educativo]. & 77 \\
\hline $\begin{array}{l}\text { Nas práticas do curso sobre Educação Popular e educador popular, encontrei-me } \\
\text { como educadora social. }\end{array}$ & 141 \\
\hline $\begin{array}{l}\text { Ser educador popular é ser um militante. Lutar por justiça, direitos, por moradia, } \\
\text { em defesa dos direitos humanos, etc. Trata-se de se dedicar [...] à luta coletiva. }\end{array}$ & 152 \\
\hline $\begin{array}{l}\text { Ser educadora social é acreditar que todos temos o mesmo direito e } \\
\text { compartilhar essa ideia. É acolher, escutar e orientar os indivíduos em situação } \\
\text { de vulnerabilidade social. O que nos constitui educador social é a contribuição } \\
\text { para o melhoramento e a transformação da sociedade através de projetos } \\
\text { e atividades, de modo a preparar o indivíduo para conviver em sociedade, } \\
\text { respeitando e lidando com regras, vivendo junto com seus companheiros. }\end{array}$ & 152 \\
\hline $\begin{array}{l}\text { Durante os quase dois anos de atuação na instituição muita coisa foi agregada } \\
\text { ao meu conhecimento; no entanto pouco sobre qual é o verdadeiro papel do } \\
\text { educador popular me foi acrescentado. }\end{array}$ & 165 \\
\hline
\end{tabular}

Fonte: As autoras.

Os fragmentos supra revelam uma aproximação com o que localizamos nas entrevistas sobre ser um educador social do SCFV.

\section{Quadro 2 - Excertos das entrevistas}

Para mim, o maior desafio é levar os educandos a se tornarem pessoas melhores, pois a
realidade de vida de muitos é de sofrimento, pois moramos numa área de risco. (Educador)

Promover a integração social, intervenção socioeducativa a pessoas ou grupos em situação de vulnerabilidade social. Utilizar de ferramentas para intervir nas problemáticas dos indivíduos.

Educação para justiça social, liberdade, igualdade, democracia, cultura e contra todas as formas de discriminação. (Educadora)

Não há SCFV sem Educação Popular, o educador social tem que levar parâmetros "novos", sem desqualificar as vivências daqueles sujeitos... isso é Educação Popular. (Coordenadora)

Ser educador social é ser um trabalhador formalizado, com carteira assinada e sem necessariamente ter vínculos com movimentos sociais. O educador popular é um militante de uma causa. Ele, normalmente, tem ou já teve vínculos com movimentos sociais populares. Ele tem a sua profissão. Ser educador popular não é profissão. (Representante da Aeppa)

Os critérios de seleção utilizados na contratação de educadores no SCFV são: ter perfil para trabalhar com crianças e adolescentes em vulnerabilidade social e ter experiência na área de atuação; de preferência ser morador da comunidade. (Dirigente)

Os critérios de seleção utilizados na contratação da coordenação do SCFV são ter pleno conhecimento e experiência no SCFV e formação na área de atuação. Ter uma linguagem popular conforme a nossa região, ter conhecimento do serviço do SCFV e, de preferência, ser moradora da comunidade. (Dirigente) 
Como podemos observar, ser educador social ou ser educador popular não tem definições claras e formuladas a partir de um estudo sobre o que significa o popular e o social na educação. Por que usar educador social, justo quando o país vive o auge do Terceiro Setor, e educador popular nos movimentos sociais? Primeiro, o educador social passa a ser reconhecido como trabalhador com registro em carteira profissional. 0 educador popular não tem esse "reconhecimento". Por um lado é importante que não o tenha, porque o educador popular, não sendo uma profissão, passa a ter um caráter de militância por algo que, nesse caso, é pela Educação Popular.

O Popular, na concepção freiriana, consoante Paulo (2018), possui um fundamento que marca a sua historicidade: a luta engajada. O educador popular, militante da Educação Popular, portanto, preocupa-se com a emancipação humana, com a dignidade e com projetos de sociedade que rompam com as desigualdades sociais, econômicas, educacionais e culturais. Ainda, conforme Paulo (2013), o educador popular pode ser um educador social, mas nem todo educador social é um educador popular. Ou seja, o educador popular pode trabalhar na escola, no hospital, em casa, na rua, no escritório de advocacia, na lanchonete e considerar-se um educador militante. Já o educador social é um profissional, e nem todos possuem um elo com a militância política. $\mathrm{Na}$ entrevista com a representante da Aeppa, ela expõe: "Ser educador popular, na Aeppa é ser um militante da Educação Popular. Por isso, acolhemos educadores sociais, educadores de creche, educadores do trabalho educativo, agente socioeducador, professores e todos os trabalhadores de contextos educativos." Nas palavras da representante, o educador popular tem uma identidade: a da luta por um tipo de educação, a Educação Popular, que significa, segundo Freire (1992, p. 21):

[...] a relação entre a clareza política na leitura do mundo e os níveis de engajamento no processo de mobilização e de organização para a luta, para a defesa dos direitos, para a reivindicação da justiça. Educadoras e educadores progressistas têm de estar alerta com relação a este dado, no seu trabalho de Educação Popular, uma vez que, não apenas os conteúdos, mas as formas como abordá-los estão em relação direta com os níveis de luta acima referidos.

A Educação Popular, como podemos verificar, está ligada às lutas por justiça social, e os educadores comprometidos com um trabalho político de relacionar conteúdo e forma junto com as intervenções sociais.

\section{UNIVERSIDADE E EDUCAÇÃO POPULAR: Reflexões a Partir das Entrevistas}

Nessa seção serão trazidos alguns excertos de entrevistas articulados à questão problematizadora: Quais dificuldades as educadoras sociais encontram para ingressar e/ou permanecer nas universidades? 
Quadro 3 - Excertos das entrevistas

\begin{tabular}{|l|l|}
\hline \multicolumn{1}{|c|}{ Grupos } & \multicolumn{1}{c|}{ Sobre Formação: falas significativas } \\
\hline $\begin{array}{l}\text { Educadoras do } \\
\text { SCFV }\end{array}$ & $\begin{array}{l}\text { Fiz um curso de Educador Social que, hoje, quem realiza é Caritas e Escola } \\
\text { de Gestão Pública. Estes dois cursos me trouxeram uma experiência } \\
\text { extraordinária para trabalhar com as crianças em sala e com os pais } \\
\text { e responsáveis. Aprendi a mediar conflitos dentro da sala e conflitos } \\
\text { familiares. } \\
\text { Mas o maior problema é que o gestor não proporciona formação. Este } \\
\text { tipo de educação crítica é prática de formação para os educadores sociais; } \\
\text { aí está o desafio; ele tem que se atualizar por conta própria, através de } \\
\text { leitura, procurar palestra, cursos sobre criança e adolescente e, se tiver } \\
\text { condições, realizar faculdade na área social. Hoje, simplesmente fazer } \\
\text { parte da comunidade não garante que seja um educador social eficiente, } \\
\text { mesmo sabendo que o diploma não garante nada, porque teoria é uma } \\
\text { coisa, mas a prática é a verdadeira faculdade. }\end{array}$ \\
\hline $\begin{array}{l}\text { Coordenadores } \\
\text { do SCFV }\end{array}$ & $\begin{array}{l}\text { Não há SCFV sem Educação Popular, o educador social tem que levar } \\
\text { parâmetros "novos" sem desqualificar as vivências daqueles sujeitos... isso é } \\
\text { Educação Popular. Há ainda a questão do reconhecimento, da valorização e das } \\
\text { próprias Organizações Sociais proporcionarem momentos de (trans) formação. }\end{array}$ \\
\hline $\begin{array}{l}\text { Dirigentes de } \\
\text { instituições }\end{array}$ & $\begin{array}{l}\text { Ainda não fiz o curso de educador social, mas nos trabalhos que realizei em } \\
\text { outros locais faltava a parceria. Para mim, o maior desafio da formação é } \\
\text { nos tornarmos pessoas melhores, pois nossa realidade de vida e de muitos } \\
\text { é sofrida. }\end{array}$ \\
\hline $\begin{array}{l}\text { Representante } \\
\text { da Aeppa }\end{array}$ & $\begin{array}{l}\text { Lutamos por formação profissional na universidade pública. Levamos o } \\
\text { tema da Educação Popular e da Pesquisa Participante. A universidade e os } \\
\text { movimentos sociais precisam estar juntos. A universidade conhece pouco do } \\
\text { educador social. A Aeppa, desde os anos 2000, tem pautado a urgência de } \\
\text { cursos de formação para educadores que atuam sem formação profissional. }\end{array}$ \\
\hline
\end{tabular}

Fonte: As autoras.

As dificuldades são variadas, objetivas (necessidade do reconhecimento do trabalhador das comunidades, falta de tempo para o educador estudar por conta das condições precárias das relações de trabalho, desinteresse do gestor e desvalorização) e subjetivas (de autotransformação).

Nas entrevistas os dirigentes não citaram a necessidade de suas formações universitárias, mas de a comunidade receber uma educação de qualidade. Já os educadores retratam o seu cotidiano do trabalho, revelando a importância dos estudos, mas a universidade parece estar distante de suas trajetórias e perspectivas. Essa identificação nos levou à fala que segue:

A Associação de Educadores Populares de Porto Alegre-AEPPA possui um trabalho que acolhe um coletivo de educadores populares que vêm lutando por formação nos diferentes níveis da educação, levando em conta a inserção social dos educadores e as concepções da Educação Popular. [...]. Os educadores que participam da AEPPA são aqueles trabalhadores que atuam em diferentes projetos sociais de cunho popular, como: educação infantil (creche comunitária), trabalho educativo, oficinas, Educação de Jovens e Adultos (EJA), Movimento de Alfabetização de Jovens e Adultos (Mova) e Brasil Alfabetizado -, acolhimento institucional (abrigos), educação de rua, trabalho socioeducativo e outros espaços não escolares (STRECK et al., 2014, p. 117-118). 
A citação supra revela o perfil de educadores participantes na Aeppa. O Quadro 3 revela a necessidade de cursos universitários para educadores que trabalham com a educação não escolar e não possuem formação profissional. As dificuldades que as educadoras e educadores sociais encontram para ingressar e/ou permanecer nas universidades são do ponto de vista estrutural, tais como: a carga horária do trabalho é extensa e não lhes sobra tempo para estudar em cursos presenciais. Ao escolherem cursos a distância terão dificuldades de custear, mesmo a mensalidade sendo mais acessível em comparação com a de cursos presenciais.

A UFRGS e a Universidade Estadual do Rio Grande do Sul não oferecem cursos noturnos no caso da Pedagogia. Outro fator limitante é a não regulamentação da profissão, o que leva ao fato de que "cada instituição contrata do jeito que quer, daí as diferenças salariais" (Representante da Aeppa). Entendemos que o acesso à educação superior depende de lutas sobre condições de trabalho dos educadores socais. Depende, ainda, de uma luta da categoria para além da Aeppa - que nasce e permanece como movimento popular e não deseja tornar-se sindicato, mas permanece lutando por formação na perspectiva da Educação Popular. No livro de Streck et al. (2014) encontramos:

Os processos de violação de direitos humanos têm estado presentes em níveis cada vez mais preocupantes. Diante desse contexto de opressão, manifestado pela precarização da vida, faz-se necessário pensar alternativas de inclusão social com intencionalidade política (p. 117).

A expressão suprarreferida representa o contexto de trabalho dos educadores sociais do SCFV e do público atendido (em situação de vulnerabilidade social). Observamos que uma das alternativas, que não é a prioritária e nem a mais importante, mas contribui para qualificar a Educação Não Escolar, é a de a Universidade conhecer para intervir nesse contexto de trabalhadores e de demanda formativa. Também destacamos que o Quadro 1, apresentado neste artigo, é uma possibilidade de dar visibilidade ao trabalho dos educadores sociais, cujos Registros de Experiências constam em um livro produzido a partir de um curso para Educadores Sociais via Aeppa e Instituto Federal do Rio Grande do Sul - Restinga. A partir do Grupo de Estudos e Pesquisa Paulo Freire e Educação Popular, da Aeppa, projeta-se a elaboração do segundo volume do livro Registros de Experiências de Educação Popular: histórias e memórias de educadoras(es) populares e educadoras(es) sociais.

\section{CONSIDERAÇÕES FINAIS}

A nossa pesquisa mostrou que a universidade não é o único espaço formativo, mas, sem ela, o educador social permanece invisível como trabalhador da Educação Não Escolar Institucionalizada. A Educação Popular, como concepção teórico-prática, defendida pela Aeppa, parece e demonstrou, pelas entrevistas, ser um elemento importante na discussão do currículo dos cursos para educadores sociais. As dificuldades que educadores e educadoras sociais encontram para ingressar e/ou permanecer nas universidades é do campo econômico. Freire $(1992,1987)$ afirma ser impossível separar a educação da política e das discussões sobre qual projeto socioeconômico e político está em voga, compreendendo os interesses de classe e as lutas que são necessárias travar para superar a opressão. 
Os autores contribuíram para a reflexão do estudo, e, com eles, podemos entender a importância da sistematização das nossas experiências (PAULO, 2018; JARA, 2016) e das relações entre universidade e Movimentos Sociais Populares. De um modo geral, as universidades discutem muito pouco a Educação Popular e as demandas dos Movimentos Sociais. Quando há esse movimento de aproximação faz-se necessário registrar essas experiências e socializá-las, sobretudo em tempos de desmonte das políticas educacionais no cenário brasileiro. A partilha de experiências entre movimento popular e universidade pode vir a contribuir para o aprofundamento do tema alusivo à formação de educadores sociais e da Educação Não Escolar. Brandão (2002) é uma das nossas inspirações quando se trata de registro de experiências em Educação Popular.

Ao analisarmos, a partir das entrevistas, as demandas formativas universitárias do educador social de Porto Alegre, trabalhador do Serviço de Convivência e Fortalecimento de Vínculos, vimos que estes desejam um curso que os torne melhores profissionais, que os ensinem sobre os temas do cotidiano do seu trabalho e a conhecer melhor as políticas sociais. Essas demandas estão associadas aos limites do trabalho do educador social e às necessidades formativas.

Existe a necessidade e urgência de discutir o tipo de formação destinada à especificidade do trabalho do educador social. Sobre essa demanda, Paulo $(2010,2013)$ vem discutindo desde as pesquisas militantes realizadas no Movimento de Educação Popular - Aeppa. Outros educadores vêm trabalhando o tema, sobretudo por conta da discussão nacional referente à regulamentação da profissão do educador social. Sugerimos a leitura do trabalho de Natali (2016).

A Aeppa tem sido um importante Movimento de Educação Popular que busca adentrar na universidade levando os temas e demandas dos educadores e educadoras sociais, entre outros. É importante, porém, que a universidade também receba os educadores sociais para que ingressem nos cursos de Graduação, Especialização e outros, objetivando dar voz e espaço a esses trabalhadores.

Desejamos que este estudo seja inspiração de outros sobre os educadores sociais do SCFV, bem como sobre o tipo e exigência de formação universitária no Brasil.

Por fim, ao apresentarmos as lutas históricas que um movimento social de Porto Alegre vem pautando junto as universidades no tocante à formação, à Educação Popular e à Educação Não Escolar Institucionalizada, acreditamos que o artigo apresentado colabora com a conexão necessária entre educação e serviço social, via Educação Popular com base em Paulo Freire.

\section{REFERÊNCIAS}

BRANDÃO, Carlos Rodrigues (org.). A questão política da educação popular. São Paulo: Brasiliense, 1980. BRANDÃO, Carlos Rodrigues. A educação popular na escola cidadã. Petrópolis: Vozes, 2002.

BRASIL: Ministério do Trabalho e Emprego. Classificação Brasileira de Ocupações: CBO-2010. 3. ed. Brasília: MTE; SPPE, 2010.

FUHRMANN, Nadia Lucia; PAULO, Fernanda dos Santos. A formação de educadores na educação não formal pública. Educ. Soc., Campinas, v. 35, n. 127, p. 551-566, abr./jun. 2014. Disponível em: http://www. cedes.unicamp.br. Acesso em: 10 out. 2016.

FREIRE, Paulo. Educação como prática da liberdade. Rio de Janeiro: Paz e Terra, 1967. 
FREIRE, Paulo. Criando métodos de pesquisa alternativa. In: BRANDÃO, C. R. (org.). Pesquisa participante. São Paulo: Brasiliense, 1983. p. 34-41.

FREIRE, Paulo. Pedagogia do oprimido. Rio de Janeiro: Paz e Terra, 1987.

FREIRE, Paulo; NOGUEIRA, Adriano. Que fazer: teoria e prática em educação popular. Petrópolis: Vozes, 1993.

FREIRE, Paulo. Pedagogia da esperança: um reencontro com a pedagogia do oprimido. Rio de Janeiro: Paz e Terra, 1992.

GIL, Antonio C. Métodos e técnicas em pesquisa social. 5. ed. São Paulo: Atlas, 1999.

GOHN, Maria da Glória. História dos Movimentos e lutas sociais. A construção da cidadania dos brasileiros. 7. ed. São Paulo: Loyola, 2013.

GOHN, Maria da Glória. Movimentos sociais e educação. 8. ed. São Paulo: Cortez, 2012.

GOHN, Maria da Gloria. Educação não-formal e cultura política. São Paulo: Cortez, 1999.

GOHN, Maria da Gloria. Educação não formal e cultura política: impactos sobre o associativismo do terceiro setor. 3. ed. São Paulo: Cortez, 2001.

GOHN, Maria da Glória. Educação não-formal e o educador social: atuação e desenvolvimento de projetos sociais. São Paulo: Cortez, 2010.

JARA, Oscar. Para sistematizar experiências. Brasília: Ministério do Meio Ambiente, 2006.

NATALI, Paula Marçal. Formação profissional na educação social: subsídios a partir de experiências de educadores sociais latino americanos. 2016. Tese (Doutorado) - Universidade Estadual de Maringá (PPE-UEM), Maringá, 2016.

PAULO, Fernanda dos Santos. Formação dos/as Educadores/as Populares de Porto Alegre Formados/as em Pedagogia: identidade, trajetória e desafios. 2010. 79f. Monografia (Especialização em Educação Popular: Gestão de Movimentos Sociais) - Instituto Superior de Educação Ivoti \& Instituto de Desenvolvimento Brava Gente, Porto Alegre, 2010.

PAULO, Fernanda dos Santos. A formação do(as) educadores(as) populares a partir da práxis: um estudo de caso da Aeppa. 2013. 273 f. Dissertação (Mestrado em Educação) - Universidade Federal do Rio Grande do Sul, Porto Alegre, 2013.

PAULO, Fernanda dos Santos; CONTE, Isaura Isabel; BIERHALS, Patricia Rutz. Educação Popular e pedagogia social: um encontro possível no caso de Porto Alegre? Educação: Teoria e Prática, Rio Claro, v. 23, n. 43, p. 128-144, maio/ago. 2013.

PAULO, Fernanda dos Santos; SANTOS, Karine. (Des)encontros entre a educação popular e a pedagogia social. Ensino \& Pesquisa, Paraná. v. 15, p. 117-140, 2017.

PAULO, Fernanda dos Santos; SEABRA, Vlamir do Nascimento; PAVANI, Gilberto João (org.). Registros de experiências de Educação Popular: histórias e memórias de educadoras(es) populares e educadoras(es) sociais: curso de extensão. Passo Fundo: Saluz, 2018. (Educação Popular: trabalho e formação de educadoras/es populares de Porto Alegre).

PAULO, Fernanda dos Santos. Pioneiros e pioneiras da educação popular freiriana e a universidade. 2018. 268 f. Tese (Doutorado em Educação) - Universidade do Vale do Rio dos Sinos, São Leopoldo, RS, 2018.

PAULO, Fernanda dos Santos. Educação popular no cenário gaúcho: contribuições para a formação de educadores sociais. Revista Cocar, Belém, v. 13, n. 25, p. 307-324, jan./abr. 2019. (Programa de Pós-graduação Educação em Educação da Uepa).

STRECK, Danilo R. et al. Educação popular e docência. 1. ed. São Paulo: Cortez, 2014.

TRIVIÑOS, Augusto Nibaldo Silva. Introdução à pesquisa em ciências sociais: a pesquisa qualitativa em educação. São Paulo: Atlas, 1987. 